\title{
An Analysis of the Application of Health Informatics in Prophetic Medicine
}

\author{
Huda Junaid* \\ Sheikh Adnan Ahmed Usmani**
}

\begin{abstract}
This research aims to analyze and examine the practices of Prophetic Medicine in the paradigm of Information Technology. Prophetic medicine is considered as an alternative medicine which is inexpensive as well as an effective way of treating the ailments which are sometimes considered as curable by other modes of medicine. The research design is cross sectional while assessing the current status of Prophetic medicine among traditional medicines and is based on content analysis. The research also identifies the obstacles in the development of Prophetic medicine among health informatics. It also proposes that how further development can be made to enhance healthcare in lives of people. The Informatics applications in Prophetic medicine are insufficient and are not participating as an active ingredient of medical guidance with IT despite of its potential as it is in a form of mostly e-health applications and websites that focus more on Prophetic traditions, spiritual healing, and Islamic obligations.
\end{abstract}

Keywords: Muhammad, treatment, spiritual, medicine, healing

\section{Introduction}

The divine revelation which has been revealed on Prophet Muhammad (peace be upon him) for the excellence of his scholarship is not mere the book of the theological discourses and a book of do and don't rather, Islam is revealed with the preferential significance: a universal message, which provides comprehensive code of conduct for human life which embraces all the dimensions of human reality and human behavior with its pragmatism.

\footnotetext{
${ }^{*}$ Ms. Huda Junaid Research Scholar, University of Karachi, Karachi

${ }^{* *}$ Mr. Sheikh Adnan Ahmed Usmani Research Scholar, University of Karachi, Karachi
} 
This is the most remarkable feature of Islam that it excels all the aspects of human nature. In fact, man is the 'Addressee of Quran'. Islam is a complete code of life, and this paved the way for Muslims to give due reverence towards Quran and Hadith. The Prophet Muhammad's (peace be upon him) words and actions are the utmost guidance for them because they are destined and revealed from Allah and are the second source of knowledge. Whether, these are related to any aspect of human life; obligations, social dealings or human living and health.

Man has been appointed as a vicegerent because he possesses the ability of intellect and desire, to carry out His mission. Allah Almighty has not only subdue every speck of the universe for man but He sketch out such circumstances through which he can complete his quest in the finest and purest form, such as promotion of all the dimensions of Health and healthy environment. Islam favors on the restoration of Health, its preservation and its prevention. There are clear evidences in this regard. ${ }^{1}$ In Quran it is stated " $O$ mankind, there has to come to you instruction from your Lord healing for what is in the breasts and guidance and mercy for the believers." ${ }^{\text {"2 }}$ It is evident with this verse that The Prophet Muhammad (peace be upon him) was a skillful Tabeeb- Doctor, and the holy Quran is a diction of all the medicines which in its ingredients cures the diseased heart. There are four steps of Tabeeb's approach to cure his patient, and these four steps are mentioned in the verse. ${ }^{3}$

Health Informatics Results in the rebirth of Prophetic medicine in such a way that the traditional practices of Sunnah in context of health is emerged as a whole new science. This science was known in Muslim community to some extent which gradually expends with the evolvement of it in terms of medicine and technology. Information technology paved the way of its veracity, efficacy and efficiency in the era of Globalization. When science has sought refuge in the umbrella of alternative medicine, tibb-e-nabawi has enlightened in the world irrespective of cast, sects and religion. It has been accepted by the people and proliferated through the media. ${ }^{4}$ People nowadays prefer to undergo with alternative treatments such as natural food remedies, change in lifestyle and habits. This is the concept of preservation and prevention of illness presented by Islam through the teachings of our beloved Prophet Muhammad (peace be upon him).

In less privileges areas and developing countries, considering health treatments 
as expensive, requiring time and hectic, people are considering Health Information Technology as a convenient packaged option. Muslims around the globe are concerning for the promotion of Islamic life style. time demands us to reassess, regenerate and reestablish the Prophetic medicine in the world of Information Technology. Let the IT perform its role in the promotion of Prophetic medicine for the goodness of mankind.

\section{Literature Review}

The researcher has gone through various related studies while writing the paper. It is aimed to examine factual and empirical literature relevant to the preset research. Ragab argues that after fifteenth century, medieval texts of prophetic medicine written by primary scholars are reinterpreted and resulting secondary texts shows the involvement and authority of modern medicine. ${ }^{5}$ Ikram examined the application of health informatics in Traditional medicine. He includes four types of medicine in Traditional medicine, among which, one is Islamic medicine. Sourcing the results from four data bases; he summed up that health Informatics in terms of traditional Arabic and Islamic medicine are "mostly e-health applications that focus more on spiritual healing, Islamic obligations and prophetic traditions". 6

On the other hand, reasons of development of Traditional Chinese medicine and Ayurveda are bioinformatics, data base for decisive system support, data mining, and image processing along with documented ISO standards. Therefore, Rumkhani proposed a domain specific ontology i.e. Tibb-e-nabawi ontology, under the slogan of 'TibbOnto'. ${ }^{7}$ This ontology is based on the authentic ahadith and copied the concept of existing Hadith ontologies namely Hadith RDF (Resource Description Framework) and hadith IJS (Isnad Judgment System). She builds a domain specific ontology to present the prophetic medicine. The presented main classes (domain) Such as disease, health, food nutrition and sub classes (range of domain) and the relationship among them through identifying the properties among their concept. For example, a class 'disease' and sub class 'treatment' has the property 'is cured by' in relation. And this entire process automatically generates treatments for specific disease according to the Prophet's actions.

Indeed, it is a data mining application which has been presented in a magnificent manner but it lacks the complete classes and sub classes and there 
is a room to include more powerful aspects of tibb-e-nabawi, such as treatment with Quranic verses and cupping therapy. Also it is mere a graphic proposal despite of an active application of domain specific ontology system. In the context of tibb-e-nabawi and cupping therapy as one of the methods practiced in the era of Prophet Muhammad (peace be upon him), another analysis is on the mode of Cupping therapy, History of cupping therapy, and the methodologies of it in light of Prophetic medicine and modern medicine. ${ }^{8}$ It is reviewed that alternative medicines are such as cupping therapy, is an effective treatment for the disease that are medically incurable.

In view of the above literature review, some questions are raised to be further explored. Whether Prophetic medicine is developing enough in the incumbency of modern trends to health Informatics? It is important to discuss what is the current status of Prophetic medicine among people, specially, Muslims approaching for it through the means of IT such as websites, applications, forum as a treatment mode in terms of diseases and treating of it? And to what extent these modes are helping people out? And last but not the least, is the extended help given are sufficient enough for the patients seeking for assistance?

\section{A brief Account of Prophetic Medicine}

In Arabic language, the word tibb is denoted as 'al-hadhaq bi al-shai' which means, perfect skill of thing while doing or performing it. ${ }^{9}$ And those who possess the skill of treatment and healing are called tabib. According to the scholars of tibb-e-Nabawi, it is defined as "medical treatments, prescriptions of diseases, prevention, health promotion and spiritual aspects that were recommended by Prophet Muhammad (peace be upon him) to his companions." 10 It is evident that these are the guidelines to achieve physical as well as moral well-being that is based on the life and deeds of Prophet. The dominance of the Prophet's medication is considered preventive medicine and considered more for preserving health rather than curing illness.

\section{Historical Background}

The term Prophetic medicine is dated back to, when Imam al Bukhari collected the hadith related to medicine under the chapter of tibb-e-nabawi. This was the initial work done in the paradigm of tibb-e-nabawi that consists of merely the collection of hadith related to the sickness and healing. There after many 
scholars collected the hadith on the same manner without further medical analyzation. After thirteenth century Prophetic medicine gained the involvement of Islamic scholars and doctors both who recognized and analyzed the efficacy of prophetic medicine. This embarked the development of hadith sciences in context of Prophetic medicine. Following three authors contributed significantly to the development of Prophetic medicine: al-Dhahabi, Ibn Qayyim al-Jawzìya, and Ibn Muflih. ${ }^{11}$

\section{Some aspects of Prophetic medicine in contrast to Science \& Technology:}

Science has made rapid improvement in developing treatment modes: Homeopathy, Allopathy, Chinese therapy acupuncture, Japanese Reiki, Yoga, herbal medicines and such others. Among these, allopathic is considered as one of the most effective one to the extent that it ranges up the hormones, but not in healing the disease completely. In fact, there are some diseases which could not be diagnosed, or in case diagnosed, remain uncured, rather of the existence of these different modes. So the need of the fulfillment of this gap was occasioned. Apart from this, the development of science has focused on prevention on the first hand. This verifies the veracity of Islam who favors the promotion of health and its preservation fourteenth hundred years ago. One can preserve his health through proper nutrition, medication, by refraining from things which leads towards illness. Thus, among the important modes of treatment, became the Prophetic medicine.

On the basis of an interview with an expert of Prophetic medicine ${ }^{12}$, Prophetic medicine is a wider term which is based on the following five aspects:

\section{Zikr:}

Zikr is an oral incantation that could be done by any one for his/herself. ${ }^{13}$ It could be by others too by blowing (one's breath on the one it is intended) after reciting some particular verse(s), by drinking its water, or blowing on hands and then moving the hands over the body. It is considered as permissible along with specified conditions, as there are clear evidences in saying of the Prophet (peace be upon him). ${ }^{14}$

\section{Quranic Therapy:}

When Allah says that: "And we send down of the Quran that which is healing and mercy for the believers, but it does not increase the wrongdoers except in 
loss." 15 So definitely this means that Quran verifies the importunity of healing. And through enthusiasm, research and analysis of many years, it has been proved that Quranic therapy is an astonishing way of treatment which is correspondent with the manners of nature and fulfils the supreme intentions of healing. And accomplish our objective: inexpensive, effective, and curative remedy and a treatment mode of Muslims. ${ }^{16}$

\section{Supplication:}

Meditation has a remarkable effect on one's health. Praying five times (salah) on daily basis is the most significant form of meditation. Many researchers have been conducted after contrasting between the patients practicing any kind of mediation including offering Salah and those who do not. Meditation immediately reduces heart rate, preventing one from heart attack, boost immunity and much more. ${ }^{17}$ It has also been monitored that brain emits healthy brain waves which are necessary in promotion of health. ${ }^{18}$

\section{Deeds of Prophet Muhammad (peace be upon him):}

Among the deeds of Prophet Muhammad (peace be upon him), was to recite Quranic verses on water which is meant to be drank by the ill person, who cures with an illness. Water is an essential element of nature which gives life to everything. It is mentioned countless times in ahadith. Water preservation is highly encouraged. ${ }^{19}$ A Japanese scientist has proposed a research of 'Crystalline water memory. ${ }^{20}$ That what happens in near surroundings of water in form of events or sounds, it is preserves by water in a form of crystalline changes which is easy to observe. It will open a new door of science if it is found that water has healing properties and it will considered as an inexpensive mode of treatment, available on hands, and without any side effects. ${ }^{21}$

\section{Treatment with Foods and Nutrition:}

Treatment with foods mentioned in Prophetic medicine is numerous. The foods mentioned by the Prophet (peace be upon him) are unique in a way that all the foods which are mentioned by him possess high nutrition components as well as they are unparalleled because they are antioxidant and antitoxin at a time. Despite of allopathic medicine, which is either antioxidant or antitoxins, this differentiates the efficiency of food mentioned in a context of health and illness mentioned by the Prophet. Same is the case with black seeds (Nigella sativa) which is mentioned by the Prophet Muhammad (peace be upon him) as a source of healing for every disease except death. Pharmaceuticals, biologists and 
physicians are prescribing it because of the "satisfactory clinical efficacy and low toxity."22

\section{Health Information Technology:}

Twenty first century is an era of Information technology, where everything available on finger tips of a man. In the field of Information Technology, every aspect of social science and humanities has put their best foot forward to be the part of it with succession. Health IT is a broad term that describes the technology and infrastructure used to record, analyze, and share health data. Health Information Technology is the significant aspect in the field in terms that it is meant to promote healthy living, lesser medical errors and to provide equal opportunity for human beings to attain benefits related to health. It works with different outlook such as e-health libraries, different medical forums to discuss information, health care applications and websites, online medical assessment, personal health blogs and health record systems. ${ }^{23}$

\section{Discussion}

Now the Question is that in the era of Information Technology, how Prophetic medicine is flourishing? To put forward this, it is important to analyze and evaluate the current position and practices of Prophetic medicine in the field of IT. The condition is as follows:

E-Narrator ahadith System has been used as a data base of Prophetic medicine. Prophetic medicine is derived from the sayings and deeds of the Prophet related to health, fitness and illness. There are various e-narrator hadith systems or websites where any text or phrase of hadith is mentioned, it automatically generates the full text and chain of narrations. ${ }^{24}$ It can assist a person in finding the treatments like cupping therapy, oil therapy or healthy prescribed foods such as honey, dates, and some fruits or vegetables etc. Although these are not the websites that are basically meant for narrations of Prophetic medicine but one can find from it. Similarly there is a system proposed TibbOnto ${ }^{25}$ that is specially designed for Ontology based system of Prophetic medicine where diseases are domains and the treatments are the ranges. With sheer disappointment, this is not an active application as mentioned earlier.

During the content analysis, the researcher finds out only one website which could be concerned as a website of Prophetic medicine in terms of Health IT. The purpose of this website ${ }^{26}$ is to create awareness that Prophetic medicine is 
a complete form of medicine which addresses both kind of disease physical and spiritual. This website seems as an initial form of e-Health library with concerned research articles and a way of professional assistant through discussion forum only. ${ }^{27}$ This system lacks basic electronic health assistance such as proper automatic database of disease and treatments, multimedia tools for patient's decision making ability or diagnosis and prescription by health practitioner of Prophetic medicine, database evidences, and open MRS (Open medical record system). Therefore, this website is confined to its purpose only.

There are various apps of Prophetic medicine enabled out of the book based applications such as based on a book of Ibn e Qayyim Al jawziyyah, ${ }^{28}$ who is a pioneer of Prophetic medicine and the book written by him about Prophetic medicine is considered as an extensive source of information for the practitioners. These apps are confined only to food nutrition, diseases and their treatments in the light of Sunnah.

In addition, the information technology in the form of E-health libraries and websites

has put a cherry on top. Health sciences libraries works by providing research and publication after clinical learning of health professionals and by providing decision making policy by professionals to patients, and to enhance the capability of patient for decision making in terms of their health condition. "The Internet, delivery of information to the desktop or mobile device, open access publishing etc. have also impacted on health sciences libraries, it is the association with "evidence", and evidence not just for health professionals but for patients and public too, that is significantly driving health sciences librarians and e-libraries in new directions." 29 These websites are providing live volunteering sessions by health practitioners.

Muslims as per their belief are already familiar with the miraculous healings from Prophetic medicines and also by practicing the teachings (Sunnah) of Prophet Muhammad (peace be upon him). Moreover, with the later advancement in the field of medicine, science and technology, Prophetic medicine affirms its veracity. People are considering Prophetic medicine as an alternative medicine which is an inexpensive as well as an effective way of treating the ailments which sometimes is considered difficult or incurable by other modes of medicine. 


\section{Conclusion}

With the research, it became evident that people are considering Prophetic medicine as an alternative medicine which is an inexpensive as well as an effective way of treating the ailments which is sometimes considered difficult or in curable by other modes of medicine. The Informatics applications in Prophetic Medicine are mostly e-health applications and websites that focus more on prophetic traditions, spiritual healing, and Islamic obligations and are not participating as an active ingredient of medical guidance with IT despite of its potential.

Literature regarding development of health informatics to support Prophetic Medicine is not sufficient. Other infrastructure such as telemedicine and Medical information systems focus its implementation in modern medicine are not strategized at an area based level for example, national level to support Prophetic Medicine. Together with all means, Practitioners and followers of Prophet medicine must cater to enhance and advance health care, education and research of it for the lives of people.

\section{Recommendations}

There is a lot to do. The professionals of Prophetic medicine must strengthen it on the foot prints of other kind of medicine modes available online. There are many online health solutions available in the form of websites, social communities and health professional platforms for example OU medicine ${ }^{30}$ which provide medical assistant through virtual programs, live volunteering and evidence based conditions and treatments. Even they assist in finding a doctor online or give directions when needed for hospital in case of emergency. Health sciences libraries must add the book of Prophetic medicine, providing research and publication after clinical learning of health professionals and by providing decision making policy by professionals to patients, and to enhance the capability of patient for decision making in terms of their health condition. The websites can provide live volunteering sessions by health practitioners of Prophetic medicine. Multiple computing and telecommunications devices from desktop to portable to wearable can be used, many of which would also be capable of supporting teleconferencing and distance education. Multimedia and tools such as podcasts, risk assessment, live online help etc. must be made part of it. Similarly, Open Medical Record system must be offered. Portals of Patients and Professionals can be established. Prophetic medicine ontology based proposals should be converted into an active website. Data mining, image 

An Analysis of the Application...

processing and ISO documentation is necessary. Quran Therapy can be conducted online or through websites by providing the recordings of the prescribed Surahs for specific illness by the practitioners of Quranic Therapy. A list of recordings, reviews of the patients and patient's history must be stored in this type of website to cater the needs of an ill person seeking for remedy with this mode of treatment.

\section{References}

1 Ibn Qayyim al-Jawziyyah. Prophetic Medicine. Lahore: An Nafees Publishers. 1999

${ }^{2}$ Al-Quran. Surah Younus, verse 57

3 Taqi ad-Din Ahmad ibn Taymiyyah. Amraaz-al Quloob wa Shifa'ohaa. Beirut: Matba'al-salafiyah.

${ }^{4}$ Fujii Chaiki. "Comparative study of the Medicine of sunnah and uganga." Kyoto Bulletin of Islamic Area Studies 4, no. 1\&2 (2011): 156-189.

Kyoto: Kyoto University. 2011.

5 Ahmed Ragab. "Prophetic Traditions and Modern Medicine in the Middle East: Resurrection, Reinterpretation, and Reconstruction." Journal of the American Oriental Society 132, no. 4 (2012): 657-73. doi:10.7817/jameroriesoci.132.4.0657.

${ }^{6}$ Raja Rina Raja Ikram. Mohd Khanapi Abd Ghani, and Noraswaliza Abdullah. "An analysis of application of health informatics in Traditional Medicine: A review of four Traditional Medicine Systems." International Journal of Medical Informatics 84, no. $11 \quad$ (2015), 988-996. doi:10.1016/j.ijmedinf.2015.05.007.

7 Al-Rumkhani, Asma, Muna Al-Razgan, and Auhood Al-Faris. "TibbOnto: Knowledge Representation of Prophet Medicine (Tibb Al-Nabawi)." Procedia Computer Science 82 (2016), 138-142. doi:10.1016/j.procs.2016.04.021.

${ }^{8}$ Salah Mohamed El Sayed. "Methods of Wet Cupping Therapy (Al-Hijamah): In Light of Modern Medicine and Prophetic Medicine." Alternative \& Integrative Medicine 02, no. 03 (2013). doi:10.4172/2327-5162.1000111.

${ }^{9}$ Ahmad ibn Ali Ibn Hajar al-Asqalani. Fath al-bari bi-sharh sahih al-bukhari. Beirut: Dar al-Kutub al-ilmiyyah, 1989.

${ }^{10}$ Nurdeng Deuraseh. "Health and medicine in the Islamic tradition based on the book of medicine (Kitab Al-Tibb) of Sahih Al-Bukhari." Journal of the International Society for the History of Islamic Medicine . 5. 2-14. 
11 Irmeli Perho. The Prophet's Medicine: A Creation of the Muslim Traditionalist Scholars. Finnish Oriental Society. 1995

${ }^{12}$ Muhammad Riaz. Tibb e Nabawi. (H. Junaid, Interviewer) dated: April 21, 2019.

${ }^{13}$ A'wadh. Ahkam Al Ruqyah Wa-Al Tama'im. Saudia Arabia: Maktabah Al'adwa Al'salaf. 1998

${ }^{14}$ Yousuf. 4 shared files. Retrieved May 27, 2019, from 4Shared

${ }^{15}$ Al-Quran. Surah Isra, verse 82

${ }^{16}$ Muhammad Riaz. Interview.

${ }^{17}$ Jonathan Smith. "Alterations In Brain And Immune Function Produced By Mindfulness Meditation: Three Caveats." Psychosomatic Medicine 66, no. 1 (2004), 148-149. doi:10.1097/00006842-200401000-00022.

${ }^{18}$ Erik Solberg. Øivind Ekeberg. Are Holen. Frank Ingjer. Leiv Sandvik. Per A. Standal, and Agneta Vikman. "Hemodynamic Changes During Long Meditation." Applied Psychophysiology and Biofeedback 29, no. 3 (2004), 213-221. doi:10.1023/b:apbi.0000039059.20738.39.

${ }^{19}$ Al-Quran. Surah Anbiya, verse 30

${ }^{20}$ Masaru Emoto. Water Crystal Oracle: Based on the Work of Masaru Emoto. Council Oaks Distribution, 2005.

${ }^{21}$ Muhammad Ans. "Healing Power of Water, Myth or Reality." Kemcolian Journal of Medical Sciences 1, no. 1 (2012)

${ }^{22}$ Hira Ijaz. Ume Ruqia Tulain. Junaid Qureshi. et al. "Review - Nigella sativa (Prophetic Medicine): A Review." Pakistan Journal of Pharmaceutical Sciences 30, no. 1 (2016), 229-234

${ }^{23}$ Basit Chaudhry. Jerome Wang. Shinyi Wu. et al. "Systematic Review: Impact of Health Information Technology on Quality, Efficiency, and Costs of Medical Care." Annals of Internal Medicine 144, no. 10 (2006), 742. doi:10.7326/00034819-144-10-200605160-00125.

${ }^{24}$ Aqil Azmi and Nawaf Al Badia. "e-Narrator - An application for creating an ontology of Hadiths narration tree semantically and graphically." Arabian Journal for Science and Engineering 35, no. 2 (2010), 51-68.

${ }^{25}$ Al-Rumkhani. "TibbOnto: ... 26

http://tibbenabawi.org/index.php?option=com_content\&view=frontpage\&Ite mid=1

${ }^{27}$ Available at: tibb-e-nabwi@googlegroups.com

${ }^{28}$ Ibn Qayyim al-Jawziyyah. 1999 
${ }^{29}$ Kate Kelly. "Health Science Libraries: future trends." An Leabharlann: The Irish Library 18 no. 1 (2009),12-17.

${ }^{30} \mathrm{OU}$ Medicine. Retrieved on May13, 2019. from OU Medicine.

https://oumedicine.staywellsolutionsonline.com/ 